\title{
Research on Hippotherapy Effects in Children whith Disabilities
}

\author{
Zamfir MARCHIȘ ${ }^{1 *}$, Camelia RĂDUCU ${ }^{1}$, Daniela LADOŞI ${ }^{1}$, Eugen $\mathrm{JURCO}^{1}$, Aurelia COROIAN ${ }^{1}$, Cristian \\ Ovidiu COROIAN $^{1}$, Luciana PRAŢA ${ }^{1}$ and Simona JURCO ${ }^{1}$ \\ ${ }^{1}$ Faculty of Animal Science and Biotechnologies, University of Agricultural Sciences and Veterinary \\ Medicine Cluj-Napoca, Romania \\ *corresponding author, e-mail: zamfirmarchis@usamvcluj.ro
}

Bulletin UASVM Animal Science and Biotechnologies 74(1)/ 2017

Print ISSN 1843-5262; Electronic ISSN 1843-536X

DOI:10.15835/buasvmcn-asb: 12213

\begin{abstract}
This paper presents a study on the interaction of children with special needs and horses, which attempts to demonstrate the effects of hipoterapy in helping children with disabilities. The research was conducted on a group of 20 children with disabilities who participated in this type of therapy for 8 months (January-August 2015) in Leorinţ Leisure Center and Riding Therapy, which owns 6 horses. This study carried out a pre- and post-evaluation and there were followed skills and cognitive function, motor skills, spatial-temporal orientation skills, sensoryperceptual organization, examining language and personality of children. In the first stage an initial assessment of children was made representing the starting point to see to what extent children are, what special needs they have and what gaps need to be recovered or what skills and qualities may be based in therapy. After 3 months of hippotherapy, in April 2015, there was made intermediar evaluation of beneficiaries to see if the intended results were achieved and where to optimise the therapy. The final evaluation was conducted in August 2015, after four months from the intermediar evaluation. After the hippotherapy was applied in children with various disabilities, we found that children move better, speak more easily, communicate and become more careful. Besides the outcomes of this hippotherapy, its results are measurable and easily to observe. Therefore, the satisfaction to participate in hippotherapy sessions and the contact with the horses offers a real joy to this children.
\end{abstract}

Keywords: disability, effects, interplay, hippotherapy, horses

\section{INTRODUCTION}

The actual meaning of the hippotherapy is about inducing treatment of certain disorders by using the horse as a living tool. Historically the word comes from the Greek word hippos (horse) and the French terapia (treatment). The American Asociation for Hippotherapy is defining the term as being "the usage of the horses movements as a tool for the kineto-, mental- and speech therapists in getting functional responses and certain disability treatment in subjects with neuro-muscular and skeleton disfunctions" (American Hippotherapy Association, 1992).

It has been previously stated that the conection between horse and child it is highly sincere and intimate. It is a connection which cannot be simulated, revealing the actual feelings and concerns in that specific moment in time. This human-animal bond it is an authentic one under the following circumstances: it is a continuous relationship; it implies mutual benefits - both to human and animal; it is a voluntary and bi-directional relationship (Rusu, 2012).

The initial phase of the hippotherapy implies relaxation and mutual body perception. Children activity is being concentrated on equilibrium, both static and dynamic and on own movements co-ordination. Thus, the subject sitting in the saddle is not actively influenced by the horses movements. However he will enjoy in a pasive manner the be- 
nefits of the activity at the sensorial level stimulated by the specific movements of the walking horse.

To the above benefits the improvement of the muscular tonus could be added. In certain paralysis situations the symmetry of the horse movements it is helpfull as well. The direct connection and interaction with the animal can be considered as well within a formative context inducing individual and social identity of the disabled human subject.

The recovery induced by hyppotherapy is enhanced also by the fact that it is performed outdoor in contrast with the traditional indor therapeutic centers. The hyppotherapy represents an enhanced context, by the presence of other animals and other persons which are not doctors or therapists but only riding instructors. Therefore, the enhanced context is represented by the fact that the interaction is related mainly to the presence of the horses, or dogs and also by the personnel which is not directly involved in the theraphy process itself (Papuc și col., 2006; Moisă și col., 2012). In the same time hypotherapy uses the horse as a living tool, that is able to stimulate neuro-muscular reactions not only through the horse movement but as well through the emotions, by the fillings which are naturally transfered from the animal to human. Thus, this type of therapy becomes one of the favorites for subjects with severe mental disorders (Ravaioli, 2004). The goal of this study was to highlight the benefits of the hyppotherapy in the treatment of certain neuro-motor disabilities, by using the horse as a therapy living tool.

However, it needs to be stated that the treatment itself needs to be taylored and addapted on case by case basis. In order to fulfill the above aim certain objectives were set. Among these would be: increasing the level of the individual authonomy of the subjects; skill development in childred with mental and motric disabilities; diminishing negative impact of the disabilities and raising self awareness.

\section{MATERIALS AND METHODS}

The study was conducted on a group of 20 children with disabilities who participated in this type of therapy (hyppotherapy) for 8 months (January-August 2015), to the Leorint Leisure Center and Riding Therapy (Table 1). The first

Table 1: The identification of subjects involved in hippotherapy

\begin{tabular}{ccccl}
\hline Nr. & Initials & Age & Sex & \multicolumn{1}{l}{ Diagnosis } \\
\hline 1. & A.D. & 8 years & M & Cerebral palsy \\
\hline 2. & B.R. & 5 years & F & Cerebral palsy \\
\hline 3. & C.M. & 7 years & F & Bilateral spastic diparesys \\
\hline 4. & C.A. & 9 years & M & Tetra paresis \\
\hline 5. & D.B. & 7 years & F & Palatoschis operated, cerebral palsy \\
\hline 6. & D.M. & 7 years & F & Down Syndrome \\
\hline 7. & E.F. & 5 years & M & Developing severe mental retardation, Tass palsy, epilepsy \\
\hline 8. & E.D. & 6 years & F & Tetra spastic dyskinetic \\
\hline 9. & G.D. & 5 year & M & Right hemiparesis, attention deficit \\
\hline 10. & M.A. & 6 years & M & Duchenne progressive muscular dystrophy \\
\hline 11. & M.N. & 12 years & M & Duchenne progressive muscular dystrophy \\
\hline 12. & M.A. & 14 years & M & Autism spectrum disorder \\
\hline 13. & N.M. & 11 years & M & Cerebral palsy, mental retardation \\
\hline 14. & P.I. & 3 years & F & Displagie spastic, psychomotor retardation \\
\hline 15. & P.M. & 6 years & M & Autistic spectrum disorder and hyperactivity disorder \\
\hline 16. & R.A. & 16 years & M & Down syndrome - trisomy 21 \\
\hline 17. & S.M. & 10 years & M & Cerebral palsy, tetra spastic \\
\hline 18. & SZ.N. & 14 years & M & Autism spectrum disorder, mental retardation / motor \\
\hline 19. & SZ.SZ & 3 years & M & Tetra spastic, severe delay in procurement \\
\hline 20. & T.V. & 5 years & M & Tetra spastic \\
\hline & & & &
\end{tabular}


phase consisted of an initial assessment of children as the starting point to see at what level the children are, where the gaps are, what skills are recoverable and what abilities may be relied on during therapy. After 3 months, in April 2015 an interim evaluation of the beneficiaries was made to see if the intended results were achieved and to make necessary changes where needed. The final evaluation was conducted in August 2015 after four months from the interim evaluation. These assessments were carried out with a psychologist and focused on skills and cognitive functions, motor skills, spatial-temporal orientation skills, sensory-perceptual organization, examining language and personality of children.

\section{RESULTS AND DISCUSSION}

The playing therapy has been applied at the Leorinţ Leisure Center and Riding Therapy. All learning experiences in childhood and emotional development occur through playing. Whether it is physical, mental, cognitive or emotional development, during hippotherapy, everything turns into a play. Several activities are organized in order to perform gymnastic exercises, such as:

- children are asked to imagine fictional trees, where they are supposed to collect various fruits. This makes it easier for the child to perform gymnastic exercises;

- recognition of colors by showing the children some circles of different colors and then asking them to name an object of that color;

- catching some colored pins on a circle that helps children learn to count and identify colors;
- improving their balance by putting some circles on a specific support;

- hand-eye coordination development by passing the ball from child to therapist, then throw it in a basket;

- horse caressing.

All these activities were performed sitting on a horse. Using the horse as a companion in the recovery of children with various disabilities can bring many benefits, because the horse is an alive and affectionate being, able to stimulate through its movements both neuro-muscular reactions and very intense feelings to the person who comes in contact with it. In terms of sensory benefits, the horse imprint movements (forward, left, right and rear), heat, specific sounds (horseshoe on sand, grass or cement always sounds different) which always arouses strong emotions and reactions from the child. The horse is able to transmit numerous neuro-sensory stimuli which help the riders feel their bodies; it establishes a body-tonic exchange that leads to the primary links of the individual with their nature and to new explorations, perceptions, sources of developing psycho-motor behaviour and individual body identity (Canali, 2004). The benefits of hippotherapy include: physical, psychological, social and educational aspects.

The charts below contain the results of the initial, intermediate and final tests of the 20 children with diagnoses of: autism spectrum disorder, cerebral palsy, muscular dystrophy, tetra-paresis, hemi-paresis and Down Syndrome, all included in the program for children's health.

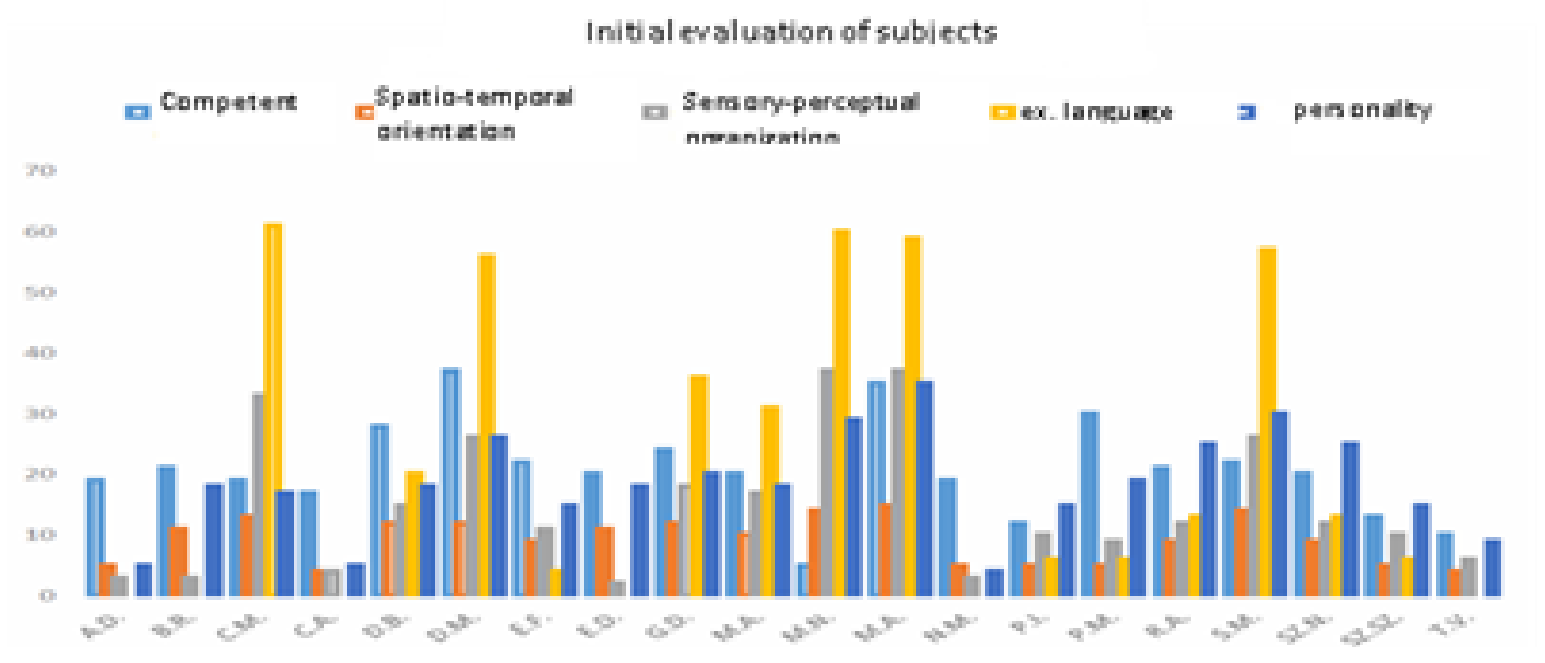

Fig. 1. Initial assessment of the subjects 
The initial assessment was made in January. These values are the starting point to see to what level the children are, what gaps they have and what must be recovered as well as on what skills and qualities the therapy may rely on.
After 3 months, in April, the interim assessment was made in order to see if the targeted results were achieved and what alterations should be performed in order to improve the achievement of the results.

The interim evaluation of subjects

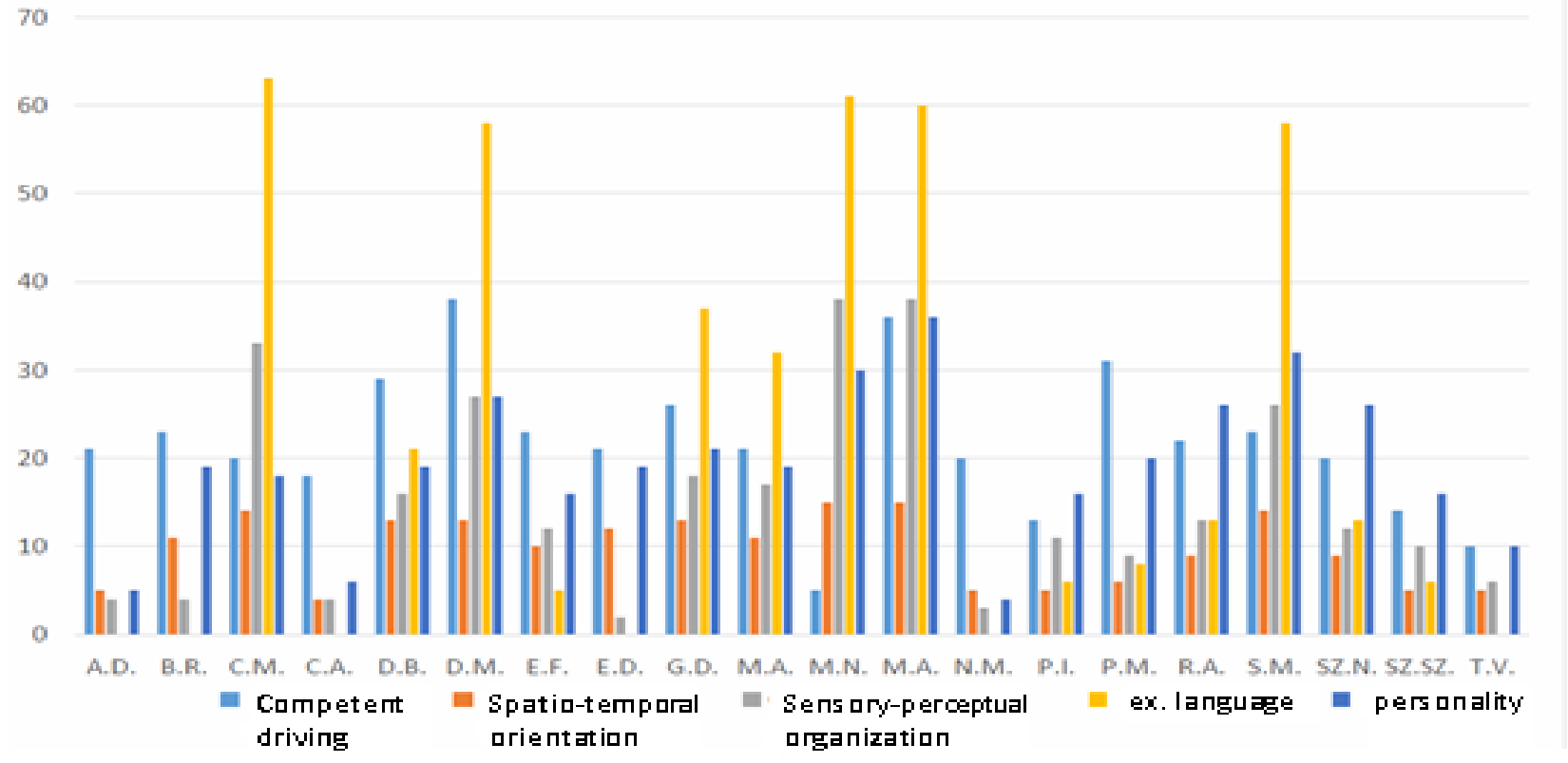

Fig. 2. The interim results of subjects

Final evaluation of subjects

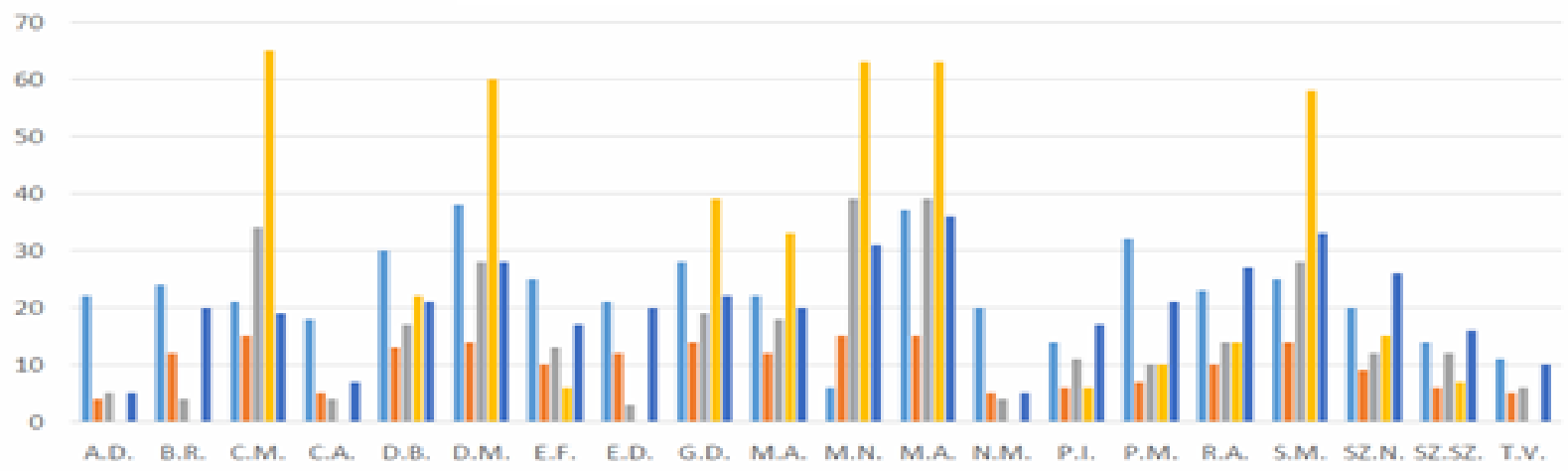

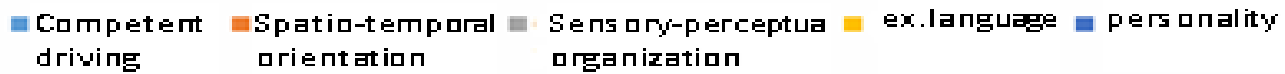

Fig. 3. The final results of subjects 
The final hippotherapy assessment was conducted in August after four months from the interim evaluation. The obtained data from each beneficiary proves an effective role for the hippotherapy. Even if not all cases reveal large variations or significant differences between the results of the three tests, any small progress gives the child a chance to better see the world around and to enjoy a new progress.

The presented results show the fact that these children move better, speak more easily, communicate and become more careful.

The age of the children represents the most important factor in the identification, diagnosis or intervention that are made by therapists. Therefore, the sooner it comes, the chances of recovery increase.

\section{CONCLUSION}

The horse based therapy, or hippotherapy represents a global effective technique at both psychomotor and social level. The fact that the hippotherapy takes place outdoors and not indoors like others classic therapies which takes place in the therapy centers or gym halls offers an stimulating environment.

Hippotherapy consists of a world which gathers horses, persons with disabilities, children and adult, volunteers and medical, psychological and educational professionals. Everybody succeeds to enrich their lives in this process.

In conclusion, all respondents would recommend others this therapy, because it meets all the demands and expectations, its positive effects being highly evident.

\section{REFERENCES}

1. Canali M (2004). Aspetti psicologici della terapia per mezzo del avallo,Societa Editrice „Il Ponte Vecchio”, Italia pag.31

2. Moisa CM, Barabasi J, Papuc I (2012). Selection Methods For Horses Used In Hippotherapy Bulletin USAMV, Veterinary Medicine, 69(1-2)/2012, 131-138

3. Ortali M (2004). L'uomo che sussurrava ai cavalli,Maestro cavallo. Un cavallo come mediatore tra me...e te!, Societa Editrice "Il Ponte Vecchio" Italia

4. Papuc I, Moisa C, Lăcătuș R, Covaciu M, Maier G, Isuf M (2006). Hipoterapia ca terapie alternativă în disfuncțiile neuropsihice ale copilului (studiu de caz) Cluj Medical veterinar, nr.10, p.10-15.

5. Ravaioli C (2004). Aspetti riabilitativi della Terapia per mezzo del cavallo; L'uomo che sussurrava ai cavalli, Societa Editrice "Il Ponte Vecchio" Italia

6. Rusu A (2012). Interacțiunea om-animal- Elemente de etologie aplicată și terapie asistată de animale,ediția a II-a revizuită, Editura Bybliotek, Cluj-Napoca.

7. American Hippotherapy Association, US, Fort Collins, 1992. 